\title{
Effects of extreme heat stress on retention in the white rat'
}

EUGENE SMITH ${ }^{2}$

NEW MEXICO STATE UNIVERSITY

White rats subjected to "extreme" heat stress showed no decrement in retention of a previously learned visual discrimination task despite a seven day decrement in running speed, and at least a $24 \mathrm{hr}$. decrement in open field activity. It was concluded that although the Ss were adversely affected by the heat stress, no loss of memory occurred.

Clinical reports concerning behavioral abnormalities following heat stroke (Weisenburg, 1912; Freeman \& Dumoff, 1944) indicate that some heat stroke patients suffer from a permanent cerebellar syndrome (neuromuscular incoordination, speech pattern defects, etc.). However, experimental evidence regarding the effects of extreme heat stress on behavior is noticeably lacking. In the present experiment, white rats were taught a successive discrimination task, subjected to experimental heat stress, and then retested for retention of the task. With this measure, as well as such performance measures as activity in the open field maze and running speed in the discrimination apparatus, it was hoped that some of the behavioral manifestations of heat stroke injury could be detected.

Method

One hundred and six male albino rats of the Holtzman strain, ranging in age from 90 to 250 days and weighing $250 \mathrm{gm}$ or less, were maintained on an ad lib food and water schedule. All of the Ss were experienced in various maze situations, but no $S$ was experienced in a discrimination apparatus.

The three pieces of equipment used were the following: a temperature chamber, an open field maze, and a Thompson-Bryant (1955) discrimination apparatus. The inside dimensions of the Statham Temperature Test Chamber used were $30 \times 8 \times 8$ in. with a $7 \times 17$ in. opening covered by a sheet of Plexiglas. $S$ was placed in a restraining device that prevented all but a minimum of movement and allowed for the convenient placement of a rectal probe. The rectal temperature of the $S$ was read from a Yellow Springs Model 41 Telethermometer. The open field maze was a white porcelein table top surrounded by a 9 in. high white Masonite wall and marked off in 3-1/4 in. squares by strips of $3 / 4$ in. black tape. Illumination was supplied by a 150-w light bulb suspended $3 \mathrm{ft}$. above the maze. The successive discrimination apparatus was patterned after Thompson \& Bryant (1955) with the following modifications: illumination was provided by a 25-w light bulb suspended $3 \mathrm{ft}$. above the top of the maze; a direct current shock of $75 \mathrm{v}$ was used as the stimulus; and equipment for measuring running time was included (a Hunter Klockounter was started by a microswitch activated by raising the start box door, and stopped when $S$ broke a photocell beam 2 in. inside the goal box door).

\section{Procedure}

Ss were trained on the successive discrimination apparatus, subjected to heat stress, and then retested 1,7 , and 13 days after stressing. Open field tests were administered and rectal temperatures were recorded prior to training and before each of the three post heat stress days.

In the open field maze, $\mathrm{S}$ was placed in the center of the maze, and the number of squares the front paws entered was recorded for $2 \mathrm{~min}$. Prior to the test, $S$ 's rectal temperature was recorded. On the following day, Ss began preliminary training following the procedure set forth by Thompson \& Malin (1961) for successive discrimination. Two days of pretraining was followed by the actual training where $S$ learned to enter the left goal box door if the discriminanda were two black cards, and enter the right door if two white cards were presented. Ss were discarded if a criterion of nine out of 10 errorless trials was not reached in 120 trials (10 trials per day). All Ss received 120 acquisition trials, regardless of when criterion was met. On the day following the completion of training, Ss were randomly assigned to three heat stress groups. By a pilot study, it was found that one half of the rats

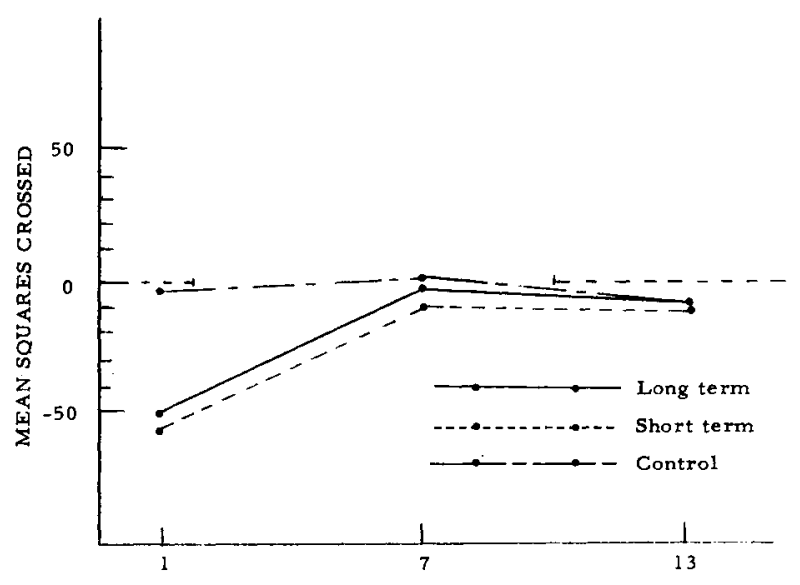

POST HEAT STRESS DAYS

Fig. 1. Difference scores in the open field tests on the three post heat stress days. 


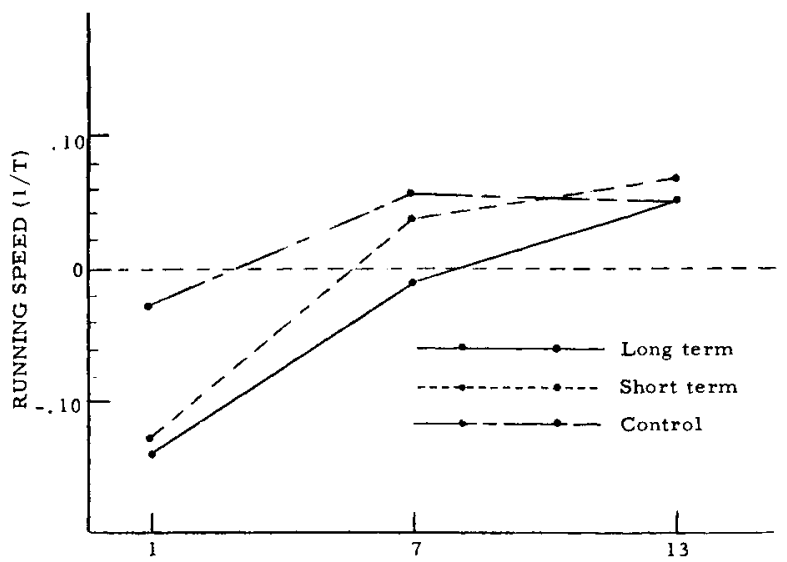

POST HEAT STRESS DAYS

Fig. 2. Difference scores of the mean running speed in the successive discrimination apparatus.

under $250 \mathrm{gm}$ died when raised to a rectal temperature of $43.0^{\circ} \mathrm{C}$ at a chamber temperature of $44.0^{\circ} \mathrm{C}$. Since the elevation of rectal temperature was reached in between 50 to $60 \mathrm{~min}$., this group was called "long term." Also, when Ss were raised to a rectal temperature of $50.0^{\circ} \mathrm{C}$, one half of the rats under $250 \mathrm{gm}$ died. Elevation to $43.5^{\circ} \mathrm{C}$ took from 18 to $21 \mathrm{~min}$., and thus, this group was named "short term." It was assumed that since these temperatures represent a $L D_{50}$, the limit of endurance for rats under $250 \mathrm{gm}$ was reached. A control group was placed in the chamber at a temperature of $40.0^{\circ} \mathrm{C}$ until the rectal temperature reached $39.5^{\circ} \mathrm{C}(10$ to $20 \mathrm{~min}$.). This was done in an attempt to equalize over all of the groups, the effects of being restrained.

\section{Results and Discussion}

The open field data were converted to difference scores (Fig. 1), and a trend test yielded a significant difference over days, $F=12.98$, df $=2 / 28, p<.001$. It was found using a Duncan's Multiple Rangle Test that the two experimental groups differed from the control group on Day 1 only, $R_{2}=8.63$, df $=87, p<.05$. The running time was converted to speed scores by reciprocal transformation and then converted to difference scores (Fig. 2). A trend test yielded a significant difference over days, $F=15.22, \mathrm{df}=2 / 28, \mathrm{p}<.001$. Again using the Duncan's Multiple Range Test, it was discovered that both experimental groups differed from the control on Day 1, but only the long term group differed from the control on Day $7, R_{2}=.036, d f=87, p<.05$. No differences were found on the thirteenth day. A trend test over the number of trials to relearn to criterion on the three post stress days yielded no significant differences among the three groups. No radical changes in rectal temperature occurred throughout the experiment.

The decrement in running speed and activity in the open field maze can be accounted for either by an increase in emotionality or as a result of the detrimental effects of heat stress. One day after the heat stress, the Ss were not difficult to handle; on the contrary, the condition of the Ss can best be described as lethargic. The fur of the animals was still matted with dirt and saliva accumulated during heat stress, indicating that the animals were too "fatigued" to groom themselves. Thus, it was assumed that the decrement was not due to emotionality, but due to "fatigue" caused by the heat stress. Since the running speed of the "long term" rats did not return to a base rate until Day 7 , it was thought that the long term heat stress was more injurious to the rats. An interesting effect of the heat stress was the paralysis of the hind legs upon removal of the Ss from the heat chamber. The paralysis lasted for $15 \mathrm{~min}$. to $1 \mathrm{hr}$. after removal.

It can be assumed from the behavioral measures as well as the observational data, that the Ss were adversely affected by the heat stress. However, even though the heat stress was potent enough to kill one half of the rats and production emporary decrement in performance, memory of the pre-heat stress visual discrimination task was not affected.

\section{References}

Freeman, W., \& Dumoff, E. Cerebellar syndrome following heat stroke. Arch. Neurol. Psychiat., 1944, 51,67-72.

Thompson, R., \& Bryant, J. H. Memory as affected by activity of the relevant receptor. Psychol. Rep., 1955, 1, 393-400.

Thompson, R., \& Malin, C. F. The effect of neocortical lesions on retention of a successive brightness discrimination in rats. $J$. comp. physiol. Psychol, 1961, 54, 326-328.

Weisenburg, T. H. Nervous symptoms following sunstroke. J. Amer. Med. Ass., 1912, 58, 2015-2017.

\section{Note}

1. The research reported here is a portion of the author's Master's thesis directed by Dr. Merrell E. Thompson, New Mexico State University, 1966.

2. Now at the Department of Psychology, University of New Mexico, Albuquerque. 